\title{
Multilinguales
}

15 | 2021

Recherches algériennes en sociolinguistique et en littérature : discours scientifique/discours militant, quelles frontières?

\section{Autour de l'acte humoristique en Algérie : le français au service de l'implicite}

Around the humoristic act in Algeria : the french language at the service of the implicit

\section{Radia Touati}

\section{OpenEdition}

Journals

Édition électronique

URL : https://journals.openedition.org/multilinguales/6166

DOI : $10.4000 /$ multilinguales.6166

ISSN : 2335-1853

Éditeur

Université Abderrahmane Mira - Bejaia

Référence électronique

Radia Touati, « Autour de l'acte humoristique en Algérie : le français au service de l'implicite », Multilinguales [En ligne], 15 | 2021, mis en ligne le 15 juin 2021, consulté le 14 février 2022. URL : http:// journals.openedition.org/multilinguales/6166; DOI : https://doi.org/10.4000/multilinguales.6166

Ce document a été généré automatiquement le 14 février 2022.

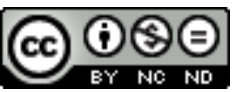

Multilinguales est mise à disposition selon les termes de la Licence Creative Commons Attribution Pas d'Utilisation Commerciale - Pas de Modification 4.0 International 


\title{
Autour de l'acte humoristique en Algérie : le français au service de l'implicite
}

\author{
Around the humoristic act in Algeria : the french language at the service of the \\ implicit
}

Radia Touati

1 L'humour a, de tout temps, accompagné les révolutions algériennes en offrant un espace matriciel de développement d'une pensée critique, et ce, en s'interrogeant et interrogeant les valeurs qui unissent les sociétés. Dans son expression spontanée, le rire a tendance à délier les langues et les pensées. La période du Hirak ${ }^{1}$ algérien est marquée par une lourde censure, qu'elle soit journalistique ou non, qui porte préjudice à la réflexion. En effet, les nombreuses arrestations connues durant cette période tendent à réprimer la créativité. El Manchar fait partie de ces médias qui ont bravé l'interdit et a multiplié les publications comme " arme redoutable. " (Dahak. B, 2018 : 15)

De ce fait, l'engagement de l'auteur apparait à travers une dénonciation par la dérision tissée dans un discours souvent implicite. En effet, face à la situation politique " tellement critiquée » du pays et le « ras le bol » exprimé par le peuple, El Manchar a su désamorcer la pression sociale offrant ainsi au peuple un moment de récréation alliant la réflexion sérieuse et le rire salutaire.

2 Par ailleurs, la problématique de l'humour nous amène à nous interroger à propos du concept lui-même et de l'effet susceptible qu'il engendre. L'humour ne fait pas forcément rire, à ce titre, l'humour peut déplaire, "L'humour, c'est le droit d'être imprudent, d'avoir le courage de déplaire, la permission absolue d'être imprudent ${ }^{3}$ ". C'est cette imprudence que s'autorise l'auteur d'El Manchar qui fait de son journal le premier en Algérie rédigé dans une tendance satirique. À cela s'ajoute le recours à du vocabulaire faisant partie de la culture algérienne (le nôtre ${ }^{4}$ ) que le chroniqueur communique à travers la langue française. Ce qui nous interpelle et nous amène à nous intéresser à la question du Même et de l'Autre dans le discours humoristique du journal 
et le rôle de la langue française dans la mise en relief de la culture algérienne et le comportement sociétal et individuel.

Ainsi, nous proposons une analyse du discours humoristique qui vise à démontrer comment l'énonciateur (El Manchar) exploite la langue française (l'Autre) afin de faire rire l'Algérien (le Même, le nôtre). Pour ce faire, nous proposons de cerner notre étude autour des questions de recherche suivantes :

- Quelles sont les caractéristiques propres au discours humoristique d'El Manchar?

- Dans quelle mesure la langue française impacte l'expression de la culture algérienne?

3 Afin de répondre à ces questions, nous proposons ces hypothèses de réponses qui nous aideront à orienter et à organiser notre travail de recherche. Ainsi, nous posons comme première supposition que le contexte socio-politique algérien représente un environnement qui se prête aux différentes dérisions qu'exploiterait El Manchar comme " arme pacifique » pour dénoncer les pratiques du régime en place. Dans un second temps, nous supposons que l'exploitation de compétences linguistiques et encyclopédiques en langue française pourrait aboutir à une structure humoristique à même de faire réagir tant le peuple, destinataire des textes, que le régime en place ciblé par le discours. Dans un troisième temps, les éléments culturels du Même et de l'Autre auxquels recourt l'auteur pourraient fournir une structure linguistique et interculturelle qui, fusionnée dans un discours humoristique, fait la particularité des textes d'El Manchar.

4 Aussi, pour vérifier nos hypothèses et répondre à nos questions de recherche, nous proposons de nous référer aux orientations théoriques de Catherine Kerbrat Orecchionni et de Patrick Charaudeau, ainsi que d'Abdallah Pretceille Martine dont les différentes définitions nous servent de balise à notre étude. Notons également que la collecte de notre corpus s'est effectuée à partir de la page Facebook ainsi que le site officiel du journal ${ }^{5}$ En tout, cinq articles ont été sélectionnés et en partie exploités dans la présente étude. Notre corpus s'est enrichi par un entretien accordé par l'auteur du journal, en l'occurrence, Nazim Baya.

\section{Quelques particularités du discours humoristique d'El manchar}

$5 \quad$ Afin de cerner les caractéristiques qui définissent les textes du journal, nous proposons un bref descriptif des acteurs d'un acte humoristique, des effets attendus et des catégories de discours humoristiques. Ces éléments descriptifs que nous empruntons à Patrick Charaudeau nous permettent de situer les écrits d'El Manchar.

\subsection{Les protagonistes de l'acte humoristique}

6 L'acte humoristique ${ }^{6}$ est une situation de communication qui met en interaction trois acteurs que Patrick Charaudeau nomme : le locuteur (chroniqueur), le destinataire et la cible.

\section{a. Le locuteur}

7 Concernant notre étude, le locuteur produit des articles dans le cadre d'un journal, de ce fait, il est considéré comme étant un chroniqueur. Ce dernier puise la légitimité de 
ses productions dans le rapport qui les lie au public cible, à savoir, un lectorat algérien âgé entre 20 et 40 ans qui comprend et lit la langue française.

Le chroniqueur d'El Manchar commente l'actualité algérienne et mondiale en ornant les textes de traits humoristiques.

" Le journal a vu le jour en 2013 sous forme d'une page Facebook avant de se doter de son propre site web en 2015 (https://el-manchar.com/). C'est un site dont l'organisation déroge aux règles traditionnelles de la presse qu'on connait jusquelà. Le fondateur du site est un jeune pharmacien algérois, Nazim Baya. À 31 ans, ce jeune développeur web a réussi à réunir des collaborateurs afin de lancer la page Facebook du journal (lancée en 2013) avant de passer à la vitesse supérieure en lançant le site web. » (Guettaf. F, Reggad Malki. F, $2017: 3$ )

8 Ainsi, d'une page Facebook qui partage quelques blagues à un site internet (crée en mai 2014), le fondateur d'El Manchar, Nazim Baya, a su imposer le discours humoristique définissant son journal comme étant « un site de fausses informations et complètement saugrenues ». En plus de s'adresser à un public spécifique ${ }^{7}$, le chroniqueur recourt presque exclusivement à la langue française pour la rédaction de ses articles, et justifie ce choix par l'aisance qu'il éprouve à rédiger en langue française plutôt qu'en langue arabe.

\section{b. Le Destinataire}

9 Les articles publiés par les collaborateurs du journal satirique El Manchar trouvent chez le public algérien un large écho. Ce dernier se vérifie à travers le nombre d'abonnés aux différentes pages sur les réseaux sociaux. Pour ne parler que du réseau social Facebook, la page El Manchar compte 514776 abonnés. Par ailleurs, le réseau social Facebook nous permet de remarquer que le public algérien n'est pas le destinataire exclusif. En effet, les articles s'adressent à tout algérien vivant ou non en Algérie, mais également, à tout citoyen du monde qui se reconnait à travers le discours de l'auteur.

10 Charaudeau évoque le public qu'il définit comme étant le " complice " du locuteur. Ainsi, le peuple " est appelée à partager la vision décalée du monde que propose l'énonciateur, ainsi que le jugement que celui-ci porte sur la cible. » (2006: 23). Ajoutons à cela le lien qui relie l'auteur du journal à ses lecteurs. Selon Patrick Charaudeau « [...] ne produit pas un acte humoristique qui veut, sans tenir compte de la nature de son interlocuteur, de la relation qui s'est instaurée entre eux, des circonstances dans lesquelles il est produit. » $(2006: 22)$

\section{c. La cible}

11 Le régime politique algérien trouve également « une place de choix » de destinataire dans les écrits d'El Manchar. En plus d'être la cible des différentes fausses informations, les dirigeants politiques algériens se voient destinataires d'un discours teinté de dérision. En effet, que ce soit pendant la période du soulèvement populaire (le Hirak) dont le déclenchement remonte au 22 février 2019, ou l'apparition de la pandémie de la COVID-19, le régime politique algérien a contribué dans une large mesure à l'inspiration du chroniqueur et a motivé la plupart des textes publiés. 


\subsection{Les portées contingentes de l'humour}

12 La connivence ludique permet de transformer la fatalité de la situation socio-politique algérienne en un discours ludique. Elle représente

« un enjouement pour lui-même dans une fusion émotionnelle de l'auteur et du destinataire, libre de tout esprit critique, produite et consommée dans une gratuité du jugement comme si tout était possible » (Charaudeau, 1996 : 36).

L'algérien, destinataire et récepteur du texte d'Al Manchar suivant : "Insolite : il prend une année sabbatique pour retirer de l'argent dans un bureau de poste " $"^{8}$, conçoit comme possible la situation décrite par l'auteur et qui met en scène un personnage fictif « Salim » qui décide de prendre un congé afin d'effectuer un retrait d'argent au bureau de poste. Cette "fausse information " est produite pour souligner la gestion des services de la poste algérienne. Cette dernière fait des files d'attente dans les bureaux de poste, un chainon interminable.

La connivence critique correspond pleinement aux écrits du journal dans la mesure où il propose au lecteur une dénonciation du régime en place. Par cette dernière, l'auteur

" cherche à faire partager l'attaque d'un ordre établi en dénonçant de fausses

valeurs » (Charaudeau, 1996 : 36).

Nous retrouvons cet effet de sens dans l'exemple suivant: " De retour au pays, Tebboune estime que l'Algérie devrait se doter d'hôpitaux " (El Manchar, 2020). L'auteur, dans cet exemple, attribue à l'actuel président de la République une préoccupation qu'il ne semble pas avoir. El Manchar suppose que Tebboune ne connait pas les hôpitaux, car inexistants en Algérie. C'est après son retour d'Allemagne, où il a effectué un déplacement, pour des soins médicaux, qu'il a eu l'idée d'en avoir dans son propre pays :

« Pour son excellence, le voyage en Allemagne était à la fois médical et spirituel. Entre deux intubations trachéales, le président a beaucoup pensé, murement réfléchi et n'a pas hésité à s'inspirer du mode de vie allemand. "Ce qui m’a frappé, ce n'est pas les routes, ni les écoles, ça on y travaille et on les aura bientôt. Mais j'ai découvert une chose toute particulière : Un établissement charitable où les citoyens reçoivent des soins. On y trouve un personnel soignant qui prend en charge des personnes malades. Ils appellent ça Krankenhaus, et en français c'est hôpital. L'Algérie devra en avoir un, ça vous évitera de mourir" a estimé le président. » (El Manchar, 2020)

Les appellations " Notre père " et "Son excellence » désignent toutes deux Abdelmadjid Tebboune, également nommé "Le président ». Nous nous sommes interrogés sur la raison de ces dénominations et leurs significations.

Concernant l'expression " notre père ", il nous semble qu'elle comporte une charge sémantique importante. En effet, le père joue un rôle primordial dans la culture magrébine, car, selon Le Camus cité par Kettani Myriam :

" l'identité paternelle comporte trois dimensions, liées au rôle du père : la présence en termes d'investissement et de stabilité [...] » $(2015: 60)$.

Le père est, de ce fait, le garant de la stabilité du foyer et le pourvoyeur de la protection. En s'en allant en Allemagne, le « père » auquel fait référence l'auteur d'El Manchar, laisse les citoyens qu'il sert, de ce fait, il n'assure pas sa place de père de la nation. C'est là que réside la " fausse valeur ». Aussi, pour l'appellation " Son excellence ", Monsieur Tebboune, dès le début de son mandat, a déclaré publiquement :

" Lors de sa prestation de serment en décembre dernier, le président avait déjà souhaité ne plus voir le terme "Son excellence" précédé son nom et prénom "Si je 
réussi, aidez-moi et encouragez-moi, et si j'ai failli, corrigez-moi. Le culte de la personnalité est révolu dans l'Algérie nouvelle", avait déclaré le chef de l'état. " .

Le président ne veut plus qu'on l'appelle par "Son excellence ", il veut se mettre sur le même plan que ses concitoyens. Néanmoins, en allant dans un pays étranger pour recevoir des soins, il montre également une autre « fausse valeur ». Il ne s'aligne pas sur le même plan que son peuple. Le journal, en l'appelant par " Son excellence » met l'accent sur cela. La connivence de dérision vise, pour effet, la dévalorisation de la cible du discours humoristique, et ce, en cherchant « à faire partager cette insignifiance de la cible lorsque celle-ci se croit importante (ou lorsqu'on croit qu'elle se croit importante) » (Charaudeau, $1996: 36)$. C'est ainsi que l'ancienne députée algérienne se voit tournée en dérision dans l'article intitulé : «Le shour'dément : je n'y suis pour rien. Naïma Salhi est juste idiote $»^{10}$. Cette ex-députée jouissait d'une immunité parlementaire due à son statut politique, ce qui lui confère une importance sur la scène politique. Ses discours, qualifiés de haineux, lui ont valu une plainte déposée à son encontre le 09 juin 2019 par des militants opposants ainsi que des avocats lui reprochant une « incitation à la haine raciale et appel au meurtre " (El Watan, 2021).

El Manchar, quant à lui, tourne le discours de l'ex-députée en dérision faisant parler « Shour »: "Outré par les propos de la députée, le shour a régi en déniant toute responsabilité quant à l'indigence politique de Naïma Salhi [...] qu'il qualifie de délirantes et de diffamatoires. ". Ce faisant, l'auteur rétablit la responsabilité des propos et désigne Naïma Salhi comme seule responsable. C'est ainsi que dans son texte, El Manchar dévalorise la députée en la qualifiant " d'idiote » dès le titre par les expressions « délirante », « diffamatoire » et « indigence politique ».

\subsection{Le triangle humoristique}

À l'image du triangle didactique de Jean Houssaye, nous constatons que le discours humoristique d'El Manchar implique, tel que le stipule Patrick Charaudeau, trois protagonistes. Nous suggérons que les interactions entre ces acteurs, souvent ornées d'éléments culturels partagés par les différents acteurs, participent à la structuration du discours humoristique.

Nous proposons le schéma suivant qui représente le processus interactif entre les protagonistes. Ceci nous amène à constater l'importance de la langue et de la culture dans la transmission du discours humoristique d'El Manchar exprimé dans la langue de l'Autre. 


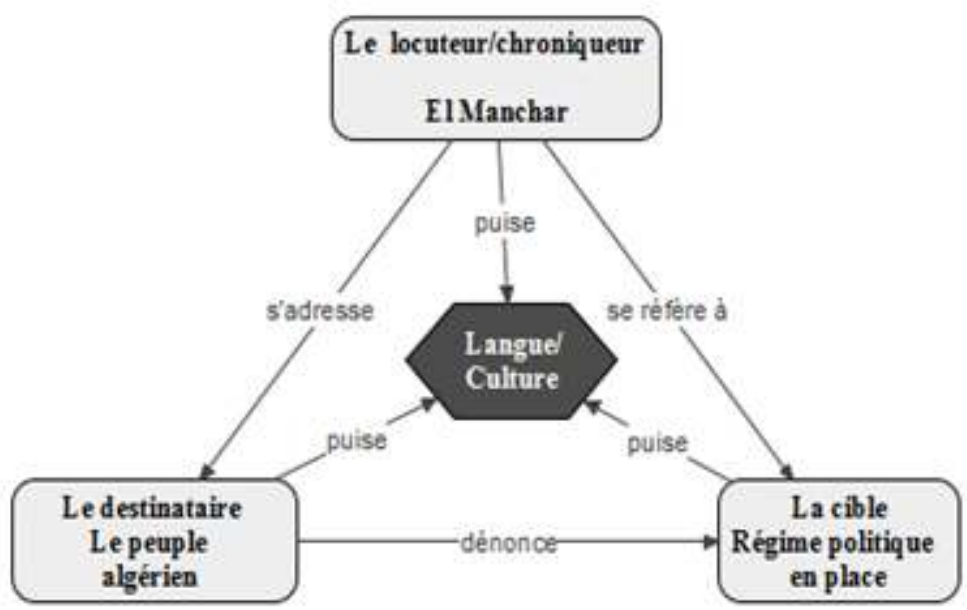

Comme nous pouvons le constater, le locuteur, également nommé chroniqueur d'El Manchar, s'adresse à un destinataire déterminé (un public algérien) et au régime politique algérien. Pour des raisons d'aisance, l'auteur use de la langue française qui véhicule sa propre culture et dont il puise ses références culturelles adaptées à la situation d'énonciation algérienne. Ainsi, le discours humoristique issu de ces rapports nommés engendre des effets différents selon que le message s'adresse au destinataire (peuple algérien) ou à la cible (également destinataire du discours).

S'agissant du peuple algérien, la réaction attendue s'exprime par une appréciation (ou pas) témoignée par le nombre d'abonnés que comptent les différentes pages sur les réseaux sociaux. Quant à la cible, qui n'adhère pas de façon systématique à la ligne éditoriale du journal, manifeste ses positions par l'instauration d'un climat de répression et de peur amenant le chroniqueur à suspendre temporairement ses publications justifiant ainsi son choix :

« [...] Cette décision a été prise par l'équipe de rédaction. Le climat de répression des libertés, les incarcérations de citoyens à la suite de leurs activités sur les réseaux sociaux nous ont conduits à réfléchir sur les risques que nous encourons ${ }^{11}[. .]$.$» .$

\section{La situation d'énonciation : autour de l'implicite}

Ce qui fait la particularité des écrits d'El Manchar, c'est la correspondance des thèmes traités à l'actualité dominante. Dans cette perspective, Charaudeau met l'accent sur l'importance de la description du contexte d'énonciation afin de mettre en évidence l'acte humoristique. En effet, pour l'auteur,

" L'acte humoristique ne se réduit pas non plus aux seuls jeux de mots comme bien des études semblent le suggérer. Les jeux de mots, s'ils relèvent en soi d'une activité ludique, ne produisent pas nécessairement un effet humoristique. Aussi est-on amené, pour étudier l'acte humoristique, à décrire la situation d'énonciation dans laquelle il apparait, la thématique sur laquelle il porte, les procédés langagiers qui 
le mettent en œuvre et les effets qu'il est susceptible de produire sur l'auditoire. » (2006: 21).

Partant de ce point de vue, Guettaf Fares et Reggad Malki Fouzia mettent en évidence la restriction du terrain d'expression en Algérie qui a vu naitre le journal satirique. En effet :

"Malgré une certaine abondance des médias arabophones et francophones dans la scène médiatique algérienne, il n'en demeure pas moins qu'elle manque de ce qu'on appelle "la presse satirique". Dès lors, force est de constater que la scène médiatique algérienne manque sévèrement d'une presse satirique proprement dite, c'est-à-dire d'une presse dotée de moyens financiers et humains considérables tels que le cas en France où ce type de presse est apparu dès l'aube de la Révolution française (1789) et représente, de ce fait, une vraie institution avec tout que cela engendre pour son image. Contrairement à la presse satirique dans d'autres pays occidentaux ou africains où plusieurs titres peuvent se disputer la scène. En Algérie, la scène de la presse satirique proprement dite est exclusivement occupée par le site El-Manchar » (Guettaf, Reggad Malki, 2017 : 3).

Ainsi, les articles publiés dans le journal traitent, principalement, de la thématique relative à la situation socio politico culturelle algérienne dont le Hirak, le soulèvement populaire est une situation des plus conjoncturelles. À ce mouvement populaire marqué par la libération de la parole tant populaire que médiatique, s'ajoute la situation sanitaire causée par la pandémie de la COVID 19.

21 La situation d'énonciation se traduit également par divers procédés langagiers qui se déploient par le recours de l'auteur à des stratégies dont: l'ironie, la dérision, le sarcasme, le non-dit. À ce sujet, Catherine Kerbrat-Orecchioni insiste sur le fait que tout implicite contient des éléments permettant d'expliciter le non-dit,

" Toute unité de contenu possède, directement ou indirectement, un support signifiant quelconque ; et même lorsqu'ils n'ont d'autre ancrage qu'indirect, les contenus implicites sont en quelque sorte "entés" sur les contenus explicites, de telle sorte que la reconnaissance des premiers présuppose l'identification des seconds » $(1986: 161-162)$.

Dans l'exemple qui suit, le chroniqueur annonce une (fausse) information relative à l'arrestation de fleuristes à Alger, «Trois fleuristes arrêtés à Alger pour complot contre la sûreté de l'État » (El Manchar, 2019). Nous pouvons lire dans l'article qui accompagne ce titre les raisons qui justifient cette arrestation :

"Trois fleuristes ont été arrêtés par l'armée lors de l'opération menée à Alger depuis hier mercredi, a-t-on appris ce jeudi 28 février de sources sécuritaires.

Cette opération a été déclenchée sur la base de renseignements faisant état de la présence de marchands de fleurs qui étaient en train de fomenter - une guerre dans le but manifeste de détruire l'Algérie- selon nos sources.

Les terro-fleuristes avaient en leur possession "des roses assez semblables à celles qui avaient servi à déclencher la guerre en Syrie”, parait-il. L'opération se poursuit sous le haut commandement du Premier ministre Ahmed Ouyahia. Le Premier ministre a mis en garde les Algériens ce matin contre les roses avec lesquelles tout a commencé en Syrie. Vous êtes prévenus, la troisième guerre mondiale aura lieu le jour de la Saint-Valentin. »

Cet extrait nous permet de relever des informations sous-entendues ${ }^{12}$ et dont le sens prend forme dès lors qu'ils sont mis en relation avec le contexte socio-politique algérien. En effet, "Il ne s'agit pas seulement de faire croire, il s'agit de dire sans avoir dit ». (Ducrot, 1972 : 15). De ce fait, recourir à des indices explicites permet d'identifier le sous-entendu de l'énonciation : 
« On peut tirer d'un énoncé des contenus qui ne constituent pas en principe l'objet principal de l'énonciation, mais qui apparaissent à travers les contenus explicites.

C'est le domaine de l'implicite. » (Maingueneau,1996:47)

Concernant notre exemple, l'énonciation du nom de l'ancien premier ministre algérien représente en soi l'indice qui permet de comprendre le sous-entendu. Ce dernier ayant fait le parallèle entre les évènements qui se passent en Algérie (le Hirak) avec ceux en Syrie pendant la guerre civile de 2011. Ces propos ont été recueillis par la journaliste Nabila Amir dans son article pour le journal El Watan en date du 02 mars 2019.

Par ailleurs, interpréter des énoncés implicites requière, selon Catherine KerbratOrecchioni l'application, aux signifiants inscrits dans l'énoncé, de diverses compétences afin d'arriver à extraire le signifié. Pour les besoins de notre étude, nous nous limiterons à quelques-unes de ces compétences, à savoir: linguistiques, encyclopédiques et rhétorico-pragmatique. La compétence réthorico-pragmatique représente, selon l'auteur, la loi de la pertinence, autrement dit, plus le texte est court mieux cela fait rire. C'est ainsi que les publications d'El Manchar, sur les réseaux sociaux Facebook et Instagram, se limitent à des énoncés d'une longueur proportionnée qui se limitent à une phrase telle que: "Des échauffourées éclatent au moment de la distribution des sandwiches cachir " (Facebook 09 février 2019), ou encore " De retour au pays, Tebboune estime que l'Algérie devrait se doter d'hôpitaux " (El Manchar 2020). Ce faisant, le contexte d'énonciation représente l'élément pertinent pour la compréhension et la transmission du message.

\section{Langue-cultures : le rire en français}

Dans l'exercice rédactionnel à visée humoristique, l'auteur relève plusieurs défis, dont celui de faire rire en utilisant une langue étrangère. El Manchar fait de l'humour avec une langue qui est Autre. La langue française est utilisée pour faire rire et devient, ainsi, un élément d'altérité, un élément partagé entre deux cultures et qui fait rire la culture qui l'emprunte :

«Une fois perçue l'originalité de l'auteur, le texte nous apparaitra également comme l'expression et la mise en forme esthétique de représentations partagées par les membres d'une même communauté. En d'autres termes, de telles œuvres peuvent constituer une voie d'accès à des codes sociaux et à des modèles culturels dans la mesure où elles représentent des expressions langagières particulières de ces différents systèmes. " (Collès, $1994: 17$ )

Faisant le parallèle avec le contexte pédagogique, Alain Cazade ${ }^{13}$ (2009) affirme que :

« Le professeur qui s'essaye à faire passer en classe une plaisanterie en langue 2 connait bien cette problématique déroutante. L'humour supporte mal d'être expliqué. Si l'on s'y hasarde, l'expérience est décevante, l'effet voulu se trouve vidé $\mathrm{du}$ charme fragile de ses ressorts humoristiques. Ces ressorts reposent souvent essentiellement sur un effet d'instantanéité, confrontant, mélangeant habilement et discrètement divers registres de langue, de situations, etc. "

La réception du message humoristique suppose le partage de certains traits culturels entre le locuteur et le destinataire pour assurer la transmission du message visé intrinsèquement. Les textes d'El Manchar regorgent d'un capital culturel à travers lequel l'auteur démontre un niveau de maitrise de la différenciation culturelle. En effet,

"Plus on est cultivé, plus nombreuses sont les distinctions qu'on est capables d'instaurer ; ou, réciproquement, plus fines sont les distinctions qu'on est capables de repérer, plus on accède à un rang culturel élevé » (Cuq, $2003: 63$ ) 


\subsection{Les éléments culturels de(s) l'Autre(s)}

Daccordé par Nazim Baya nous a permis de relever les références qui motivent et nourrissent le modèle type du discours humoristique d'El Manchar. En effet, l'auteur trouve chez l'humoriste Pierre Desproges ${ }^{14}$ un archétype d'humour noir au discours anticonformiste et au sens de l'absurde. Desproges est également célèbre pour sa singulière aisance littéraire, ce qui, à notre sens, procure au chroniqueur d'El Manchar une source intarissable de compétence encyclopédique et culturelle.

Cette capacité se traduit par le fait que l'auteur exploite avec finesse des éléments culturels solubles dans la formulation de ses blagues. À ce sujet, Catherine KerbratOrechionni ajoute :

" [...] la compétence encyclopédique se présente comme un vaste réservoir d'informations extra-énonciative portant sur le contexte ; ensemble de savoirs et de croyances, système de représentations, interprétations et évaluation de l'univers référentiel $[. .$.$] » (1982: 162)$

Ce bagage cognitif est mobilisé dans un ensemble d'informations injectées dans le texte de l'auteur, et trouve tout leur sens lors des opérations de décodage. C'est ainsi que le 07 avril 2020, El Manchar écrit : " Face à la pénurie des masques, la France autorise le port du niqab. ".

La pandémie de la COVID-19, thème qui a inspiré au journal satirique une multitude de publications, offre un contexte de mélange de culture dans la mesure où chaque pays dans le monde opte pour des solutions visant à réduire la propagation du virus. L'auteur d'El Manchar puise dans cette diversité (solution-culture) afin de construire son discours humoristique. Ainsi, l'élément culturel français, représenté à travers le principe de laïcité, est repris dans l'article comme suit :

« [...]Une vraie catastrophe qui a conduit certains pays à renoncer à leurs principes pour endiguer le problème.

- Avec le Covid-19, il n'y a ni laïcité... niqab -

L'un des premiers pays à avoir tout osé pour trouver une solution à la pénurie des masques est la France. En effet, par la voix de son Premier ministre, l'Hexagone, qui a loupé le coche à plusieurs reprises dans la politique d'achat et de distribution des masques, a décidé de faire fi d'un principe qui lui est cher : la laïcité. »

Plus loin, Nazim Baya fait référence aux idéologies du parti politique français le Front National, connu pour son rejet pour les cultures étrangères fondamentalistes susceptibles d'endiguer leur propre culture, à savoir, la culture française. À l'exemple du niqab (voile intégrale) perçu comme une menace. Comme nous pouvons le constater dans le propos suivant :

"Une source hospitalière nous a confirmé qu'en apprenant cette décision, Marine

Le Pen a été admise aux urgences suite à un malaise politico-idéologique. "

(El Manchar. 2020)

Cet exemple met en relief un va-et-vient entre deux cultures, à savoir, celle du Moyen Orient exprimée à travers le voile intégral, et la politique française de l'extrême droite. Cette ligne de conduite a été détournée pour dénoncer une idéologie extrémiste basée sur un discours qui implique l'exclusion de l'Autre ${ }^{15}$.

En somme, pour faire rire, El Manchar convoque non seulement des aspects de la culture algérienne qu'il tourne en dérision, mais aussi des aspects de la culture de l'Autre (des autres cultures) qu'il adapte à l'actualité algérienne. Notons l'exemple de l'article publié le 25 septembre 2020, intitulé : "oui-oui ${ }^{16}$ rejoint l'assemblée populaire 
nationale " où l'auteur associe oui-oui, personnage fictif de dessins animés français, aux membres de l'APN algérienne afin de dénigrer ces derniers, réputés pour leurs votes oui, provoquant ainsi un processus en miroir ${ }^{17}$ qui transmet la culture du Même à travers l'élément culturel de l'Autre représenté.

\subsection{Les éléments culturels du Même}

Le croisement entre la forme, qui est la langue française, et le fond, qui est la culture algérienne, constitue un réservoir interculturel qui offre un champ d'expression et de questionnement portant non seulement sur la culture de l'Autre, mais amène aussi à réfléchir à propos de la culture du Même. Abdallah Pretceille précise à ce sujet :

« Le discours interculturel induit un questionnement autant sur les autres cultures, sur autrui, que sur sa propre culture. C'est ce processus en miroir qui fonde la problématique interculturelle » $(1999: 28)$.

Ainsi, ce serait la langue de l'Autre, en tant qu'élément culturel, qui donnerait de la distance afin d'appréhender une réalité (nôtre réalité) de façon à lui impulser une note humoristique.

Parmi les personnages politiques algériens ayant multiplié des déclarations burlesques, une ex-députée algérienne se distingue à travers ses publications, considérées par plusieurs Algériens cuisantes et criardes provoquant ainsi une agitation populaire. En réponse à l'absurdité de la situation, El Manchar publie le 06 septembre 2020: "Le Shour dément : je n'y suis pour rien. Naïma Salhi est juste idiote. ". Le chroniqueur se lance sur les pas de La Fontaine, et ce, en faisant parler " la sorcellerie " pour tourner en dérision les dernières déclarations de la députée. La personnification de ce schème culturel enclenche la problématique du double sens et installe une ambigüité d'ordre métalinguistique. Ainsi, l'auteur dénonce le fait que la députée se réfugie dans la sorcellerie pour justifier ses dérapages sur la scène politique en jetant la pierre sur un élément culturel relatif aux croyances populaires, à savoir, la religion.

Par ailleurs, le recours aux jeux de mots et à l'implicite est constamment présent dans les articles humoristiques d'El Manchar. En effet, dans un autre exemple qui date du 14 novembre 2020, l'auteur s'exprime à propos du manque de liquidité (financière) dans les bureaux de poste ainsi que les banques algériennes. C'est ainsi que dans l'article intitulé "Insolite: il prend une année sabbatique pour retirer de l'argent dans un bureau de poste ", l'Algérien reconnait implicitement, de prime abord, l'aspect inscrit dans la culture nationale qui consiste à subir des chaines interminables pour le retrait d'agent. Ce phénomène est d'autant plus marqué par l'interculturel dans la mesure où l'auteur fait appel à un jeu de mots exprimé dans la langue de l'Autre, soit le français, afin de tourner en dérision cette situation. Ce jeu de mots consiste à comparer les liquidités financières au liquide (substance qui tend à couler).

« C'est la dernière goutte de liquidités qui a fait déborder le vase. Salim, 35 ans, cadre dans une entreprise publique est aujourd'hui à sec. Il n'a pas pu retirer son argent depuis juillet dernier. Aujourd'hui, il décide de jouer sa dernière carte pour pas crever de faim : Prendre une année sabbatique.

"Vous n'allez pas me croire, mais il me reste 45 dinars en tout et pour tout. Il y a plus de liquidités dans la poche urinaire de Boutef que dans les poches de mon pantalon. Je ne pensais pas que l'on pouvait en arriver là, mais je n'ai pas trop le choix, je prends un congé pour retirer enfin mes 3 derniers salaires" lâche-t-il en détresse. » (El Manchar, 2020) 
Le message intrinsèque, dans cet exemple, fait référence de manière implicite au manque de liquidités dans les banques, causé par le détournement d'argent par le régime politique algérien, celui du Président de la République déchu notamment.

Enfin, par le choix du récit de l'aventure de Salim, personnage fictif, l'auteur met en place la métaphore du mémoire, reprise par le terme de " reflet » de toute une société qui se voit confrontée à son propre parcours en se représentant la réalité quotidienne propre à la culture algérienne. Une stratégie pédagogiquement humoristique qui invite le destinataire, à savoir le peuple, à une révolte douce et à un éveil salvateur. L'objectif de notre étude visait à démontrer comment l'énonciateur (El Manchar) exploite la langue française (l'Autre) pour faire rire l'Algérien (le Même, le nôtre), et ce, à travers une analyse du discours qui met l'accent sur la façon dont la langue française fait ressortir des traits de la culture algérienne et des comportements spécifiques aux Algériens.

Au terme de notre étude, nous pouvons confirmer que le discours humoristique est une écriture créative. D'une part, elle fait appel à des compétences linguistiques qui se manifestent dans la tribune d'El Manchar à travers l'expression implicite des messages ainsi que les divers jeux de mots que nous avons relevés au cours de notre analyse. D'autre part, la compétence encyclopédique se traduit par le recours aux éléments culturels tant algériens (le Même) que français (l'Autre). Ces compétences ont permis aux chroniqueurs de tisser des textes résultants d'une polyphonie culturelle qui offre un espace de cohabitation pour créer une association d'éléments culturels appartenant à l'un et l'autre dans une symbiose créative. Le corpus analysé, constitué de certains écrits d'articles issus du journal El Manchar, nous a permis de mettre en avant une image « sommaire » d'une sorte d'inclusion de la langue de l'Autre. Avec sa dimension culturelle, le français a permis d'exprimer et de distinguer la culture du Même par la voie de procédés linguistiques tels que les jeux de mots, véhiculant l'implicite et la dérision, dont le rapport signifiant-signifié a engendré un humour adopté par le destinataire.

\section{BIBLIOGRAPHIE}

abdallah pretceille, Martine, L'Éducation interculturelle, PUF, Paris, 1999.

ait ouarabi, Mokrane, "Plainte contre Naïma Salhi : L'instruction relancée ", El Watan, 2021, Disponible sur [https://www.elwatan.com/edition/actualite/plainte-contre-naima-salhilinstruction-relancee-11-03-2021] Consulté 10-09-2020.

amir, Nabila, « Les manifestants répondent à Ahmed Ouyahia : L'Algérie n'est pas la Syrie ", El Watan, 2019. Disponible sur [https://www.elwatan.com/edition/actualite/lalgerie-nest-pas-lasyrie-02-03-2019.] Consulté le 09-12-2020.

cazade, Alain, « L'interculturel est-il soluble dans l'humour ? », Cahiers de l'APLIUT, vol. XXVIII N², 24-39, 2009. Disponible sur [https://journals.openedition.org/apliut/1067] consulté le 01-12-2020. 
charaudeau, Patrick, « Des catégories pour l'humour ?", Revue Questions de communication, $\mathrm{n}^{\circ}$ 10, Presses Universitaires de Nancy, Nancy, 2006. URL : http://www.patrick-charaudeau.com/ Des-categories-pour-l-humour,93.html] consulté le 08-12-2020.

cuq, Jean Pierre, Dictionnaire de didactique de langue étrangère et seconde, CLE International, Paris, 2003.

dahak, Bachir, Les Algériens, le rire et la politique de 1962 à nos jours, Éditions Frantz Fanon, Tizi Ouzou, 2018.

collès, Luc, Littérature comparée et reconnaissance interculturelle, De Boeck-Duculot, Bruxelles, 1994.

ducrot, Oswald, Dire et ne pas dire : Principes de sémantique linguistique, Paris : Hermann, Coll. « Savoir ", 1972.

El Manchar, «Insolite : il prend une année sabbatique pour retirer de l'argent dans un bureau de poste ", 14 novembre 2020. Disponible sur [https://el-manchar.com/2020/11/un-algerien-prendune-annee-sabbatique-pour-retirer-de-largent-dans-un-bureau-de-poste/], consulté le $15 / 12 / 2021$.

El Manchar, « Le Shour dément “Je n’y suis pour rien. Naïma Salhi est juste idiote” », 06 septembre 2020, [https://el-manchar.com/2020/09/le-shour-dement-je-ne-suis-pour-riennaima-salhi-est-juste-idiote/] Consulté le 01-12-2020.

El Manchar, « Oui-oui rejoint l'assemblée populaire nationale », 25 septembre 2020 [https://elmanchar.com/2020/09/oui-oui-rejoint-lassemblee-populaire-nationale/ ] Consulté le 20-11-2020.

El Manchar, « De retour au pays, Tebboune estime que l'Algérie devrait se doter d'hôpitaux. », 12 novembre 2020 [ https://el-manchar.com/2020/11/de-retour-au-pays-tebboune-estime-quelalgerie-devrait-se-doter-d'hopitaux/ ] Consulté le 10-12-2020.

El Manchar, « Face à la pénurie des masques, la France autorise le port du niqab. », 07 avril 2020, [ https://el-manchar.com/2020/04/face-a-la-penurie-des-masques-la-france-autorise-le-port-duniqab/ ] Consulté le 13-10-2020.

filali, Zeineb, « Algérie : le président Tebboune met fin à une expression aussi vieille que l'indépendance. », Financial Afrik, 23 avril 2020. Disponible sur [https://www.financialafrik.com/ 2020/04/23/algerie-le-president-tebboune-met-fin-a-une-expression-aussi-vieille-quelindependance/] Consulté le 22-09-2020.

guettaf, Fares, reggad Malki, Fouzia, « Approche polyphonique de l'ironie dans la presse satirique algérienne : cas du journal d'information satirique El-Manchar », International Journal of Innovative Research in Human Sciences, VOL1. ISSUE1, 2017 001-016. Disponible sur [https:// oasesvox.com/journals/index.php/ijirhs/article/view/3/3], consulté le 15/05/2021.

kerbrat-orecchioni, Catherine, L'implicite, Paris : Armand Colin, 1986.

kettani, Myriam, «Identité paternelle en contexte d'immigration magrébine en France : des pères immigrés aux pères issus de l'immigration », Alterstice, 2015. 5(1), 57-68. Disponible sur [https://www.journal.psy.ulaval.ca/ojs/index.php/ARIRI/article/viewFile/ Kettani_Alterstice5 \%281 \%29/129\#: : :text =Selon \%20Le \%20Camus \%20 (2005) \% 2C, \%C3 \%A0 \%20celui \%20de \%20la \%20m \%C3 \%A8re.] Consulté le 15-12-2020. maingueneau, Dominique, Les termes clés de l'analyse du discours, Paris : Ed Seuil, Coll. « Mémo : Lettres », 1996. 


\section{NOTES}

1. Terme employé pour désigner le mouvement de protestation populaire qui a débuté en Algérie le 22 février 2019.

2. Boualem Sensal fait référence ici à l'humour politique qu'il considère comme dérangeant vis-àvis des gouvernants tant qu'ils sont à l'afflux des éléments susceptibles d'éveiller la conscience populaire et déstabiliser le régime en place.

3. Pierre Desproges, l'Évènement du jeudi 2 octobre 1986. Citation disponible sur le lien : https:// www.mon-poeme.fr/citations-pierre-desproges/

4. Exprime mon appartenance à cette culture.

5. https://el-manchar.com/, La page Facebook est disponible à l'adresse suivante: https:// web.facebook.com/dz.manchar/ ?_rdc =1\&_rdr

6. Expression empruntée à P. Charaudeau, Des catégories pour l'humour? questions de communication, 2006, 10, 19-41

7. Nazim Baya nous a accordé un entretien le 27 décembre 2020 au cours duquel il précise que ses articles s'adressent à un public qui lit et comprend la langue française.

8. https://el-manchar.com/2020/11/un-algerien-prend-une-annee-sabbatique-pour-retirer-delargent-dans-un-bureau-de-poste/14 Novembre 2020

9. Terme issu de l'arabe dialectale qui signifie « sorcellerie ».

10. El Manchar, Le Shour dément " Je n'y suis pour rien. Naïma Salhi est juste idiote ", 2020, https://elmanchar.com/2020/09/le-shour-dement-je-ne-suis-pour-rien-naima-salhi-est-juste-idiote/

11. Propos recueillis à partir de la page officielle Facebook du journal El Manchar qui date du 14 mai 2020. Le poste est consultable à l'adresse suivante : https://www.facebook.com/dz.manchar/ posts/1358694924320507/

12. À savoir, le recours des manifestants algériens à la distribution de fleurs aux éléments de la police. Ces fleurs sont associées par l'auteur d'El Manchar à la fête de l'amour (La Saint-Valentin).

13. Adresse URL : https://journals.openedition.org/apliut/1067

14. Pierre Desproges est un journaliste humoriste français né le 9 ai 1939, décédé le 18 avril 1988, connu pour son humour chicanier.

15. L'Autre ici étant identifié comme celui émanant de la culture française.

16. Oui oui est un personnage fictif de livre et dessins animés pour les enfants, créé par le romancier britannique Enid Blyton. Le dessin animé est adapté en langue française, pour la première fois, en 1962.

17. Concept emprunté à Abdellah Pretceille

\section{RÉSUMÉS}

Cet article suggère une analyse du discours humoristique du journal satirique algérien « El Manchar ». Notre étude est principalement basée sur deux compétences, linguistique et encyclopédique en langue française qui permettent de mettre en relief l'impact d'une interaction culturelle qui allie la langue de l'Autre (la langue française) destinée à provoquer l'humour chez le public algérien (le Même, le nôtre, le mien) en période de Hirak et de la COVID-19.

This article suggests an analysis of the humorous discourse of the Algerian satirical newspaper "El Manchar". Our study is principally based on two skills, linguistic and encyclopedic in the 
French language which allow us to highlight the impact of a cultural interaction combining the language of the Other (the French language) intending to create humor in the Algerian public audience (the Same, ours, mine) in the period of Hirak and COVID-19.

INDEX

Mots-clés : discours, El Manchar, humour, implicite, interculturalité

Keywords : speech, El Manchar, humor, implicit, interculturality

\section{AUTEUR}

\section{RADIA TOUATI}

Faculté des Lettres et des Langues, Université A. Mira, Bejaia. Algérie 